OPEN ACCESS

Edited by:

Nazareno Paolocci,

Johns Hopkins University,

United States

Reviewed by:

John W. Calvert,

Emory University School of Medicine,

United States

Ragnar Huhn,

University Hospital of Düsseldorf,

Germany

*Correspondence:

Natacha Fourny

natacha.fourny@uclouvain.be

Specialty section:

This article was submitted to

Clinical and Translational Physiology,

a section of the journal

Frontiers in Physiology

Received: 30 January 2021

Accepted: 12 April 2021

Published: 27 May 2021

Citation:

Fourny N, Beauloye C, Bernard M, Horman S, Desrois $M$ and Bertrand $L$ (2021) Sex Differences of the Diabetic

Heart. Front. Physiol. 12:661297.

doi: 10.3389/fphys.2021.661297

\section{Sex Differences of the Diabetic Heart}

\author{
Natacha Fourny ${ }^{1 *}$, Christophe Beauloye ${ }^{1,2}$, Monique Bernard ${ }^{3}$, Sandrine Horman ${ }^{1}$, \\ Martine Desrois ${ }^{3}$ and Luc Bertrand ${ }^{1}$
}

1 Pôle de Recherche Cardiovasculaire, Institut de Recherche Expérimentale et Clinique, Université catholique de Louvain, Brussels, Belgium, ${ }^{2}$ Division of Cardiology, Cliniques Universitaires Saint-Luc, Université catholique de Louvain, Brussels, Belgium, ${ }^{3}$ Aix-Marseille University, CNRS, CRMBM, Marseille, France

Type 2 diabetes is a chronic disease associated with micro- and macro-vascular complications, including myocardial ischemia, and also with a specific and intrinsic cardiac dysfunction called diabetic cardiomyopathy (DCM). Both clinical and animal studies demonstrate significant sex differences in prevalence, pathophysiology, and outcomes of cardiovascular diseases (CVDs), including those associated with diabetes. The increased risk of CVDs with diabetes is higher in women compared to men with $50 \%$ higher risk of coronary artery diseases and increased mortality when exposed to acute myocardial infarction. Clinical studies also reveal a sexual dimorphism in the incidence and outcomes of DCM. Based on these clinical findings, growing experimental research was initiated to understand the impact of sex on CVDs associated with diabetes and to identify the molecular mechanisms involved. Endothelial dysfunction, atherosclerosis, coagulation, and fibrosis are mechanisms found to be sex-differentially modulated in the diabetic cardiovascular system. Recently, impairment of energy metabolism also emerged as a determinant of multiple CVDs associated with diabetes. Therefore, future studies should thoroughly analyze the sex-specific metabolic determinants to propose new therapeutic targets. With current medicine tending toward more personalized care of patients, we finally propose to discuss the importance of sex as determinant in the treatment of diabetes-associated cardiac diseases to promote a more systemic inclusion of both males and females in clinical and preclinical studies.

\footnotetext{
Keywords: type 2 diabetes, cardiovascular diseases, sex differences, gender differences, ischemic heart diseases, personalized care, cardioprotection, diabetic cardiomyopathy
}

\section{INTRODUCTION}

An alarming report from the International Federation of Diabetes recently highlighted that prevalence of diabetes keeps increasing worldwide, affecting 463 million people in 2019 (International Diabetes Federation, 2019). Cardiovascular (CV) complications remain the predominant causes of morbidity and mortality among diabetic patients with an increased risk of heart failure, coronary artery diseases (CADs), myocardial infarction (MI), diabetic cardiomyopathy (DCM), and stroke (American Diabetes Association, 2015). Despite an estimated prevalence of diabetes slightly lower in women in comparison with men (9 vs. 9.6\%) (International Diabetes Federation, 2019), strong evidence suggests worse CV consequences and mortality in diabetic women, independent of age. Consequently, there is a growing 
interest for a better understanding of the molecular mechanisms involved in this phenomenon (Kautzky-Willer et al., 2016).

\section{IMPACT OF ESTROGENS ON CARDIOVASCULAR SYSTEM}

Multiple studies show that female hormones, particularly estrogens, have a beneficial effect on CV health (Dantas et al., 2012; Kander et al., 2017). Estrogen receptors ER $\alpha$ and ER $\beta$ are expressed in endothelial cells, vascular smooth muscle cells, and cardiomyocytes of both sexes (Cid et al., 2002; Iorga et al., 2017). Estrogens can affect lipid metabolism, energy balance, fat distribution, insulin sensitivity, and blood pressure and increase bioavailability of nitric oxide (NO) (Cid et al., 2002; VenturaClapier et al., 2017a). Estrogens also positively regulate vascular relaxation factors, such as prostaglandin I2. Therefore, estrogen has the ability to positively regulate $\mathrm{CV}$ risk factors, such as obesity, hypertension, and glucose mishandling. Studies on ovariectomized animals demonstrate greater impairment of left ventricular function following an ischemia-reperfusion episode with an implication of apoptosis, pro-inflammatory cytokines, and reactive oxygen species (ROS). Treatment with estrogens resulted in restoration of cardiac function, indicating a potential cardioprotective role of female sex hormones (Lagranha et al., 2010; Yang et al., 2018).

Compared with men, women have a higher percentage of fat mass, primarily accumulating in the subcutaneous area (Power and Schulkin, 2008). Estrogens modulate fat distribution through the expression of their receptors. Of interest, a higher ER $\alpha / E R \beta$ ratio has been shown to correlate with lower adiposity, especially at the visceral level (Davis et al., 2013). Importantly, healthy women present lower intracardiac lipid levels than men (Huang et al., 2017), and male sex is a predictor of myocardial steatosis (Kannel and McGee, 1979; Iozzo et al., 2009). Thus, favorable distribution of fat participates in CV health in women. Another important point is the lower blood pressure from adolescence onward, due to $27 \%$ less renin system activity (Blenck et al., 2016). Hypertension is a well-known CV risk factor affecting both sexes but with higher incidence and severity in men (Kjeldsen, 2018). Endogenous estrogen maintains vasodilation, contributing to the control of blood pressure in premenopausal women (Garcia et al., 2016).

\section{INCREASED RISK IN CARDIOVASCULAR COMPLICATIONS IN TYPE 2 DIABETIC WOMEN}

Several parameters linked to sexual dimorphism could contribute to higher CV risk in type 2 diabetic (T2D) women in comparison to T2D men (Table 1 ).

A role of estrogen and its receptors has been evocated to explain the higher CV risk found in T2D women. Increased expression of $\operatorname{ER} \beta$ compared with $E R \alpha$ is associated with increased oxidative stress, inflammation, and atheromatous plaque formation (Xing et al., 2009), leading to the development
TABLE 1 | Sexual dimorphism in cardiovascular risk factors in absence or presence of diabetes.

\begin{tabular}{|c|c|c|c|}
\hline & Male & Female & References \\
\hline \multicolumn{4}{|l|}{ Absence of diabetes } \\
\hline \multicolumn{4}{|l|}{ Lifestyle } \\
\hline $\begin{array}{l}\text { Food intake and energy } \\
\text { expenditure }\end{array}$ & $\uparrow$ & $\downarrow$ & $\begin{array}{l}\text { Kautzky-Willer et al., } \\
2016\end{array}$ \\
\hline $\begin{array}{l}\text { Risk of T2D with } \\
\text { consumption of sugary } \\
\text { drinks }\end{array}$ & - & $\uparrow$ & Eshak et al., 2013 \\
\hline Physical activity and Ml risk & $\downarrow$ & $\uparrow$ & Kriska et al., 2006 \\
\hline Smoking and CADs risk & $\downarrow$ & $\uparrow$ & Thomas, 2017 \\
\hline Smoking and diabetes risk & $=$ & $=$ & Willi et al., 2007 \\
\hline \multicolumn{4}{|l|}{ Fat distribution } \\
\hline Fat percent & $\downarrow$ & $\uparrow$ & $\begin{array}{l}\text { Power and Schulkin, } \\
2008\end{array}$ \\
\hline Preferential localization & Visceral & Subcutaneous & $\begin{array}{l}\text { Power and Schulkin, } \\
\text { 2008; Blüher, } 2013\end{array}$ \\
\hline Ectopic cardiac fat & $\uparrow$ & $\downarrow$ & $\begin{array}{l}\text { Kannel and McGee, } \\
\text { 1979; lozzo et al., } 2009\end{array}$ \\
\hline \multicolumn{4}{|l|}{ Blood pressure } \\
\hline $\begin{array}{l}\text { Basal systolic and diastolic } \\
\text { blood pressure }\end{array}$ & $\uparrow$ & $\downarrow$ & $\begin{array}{l}\text { Blenck et al., 2016; } \\
\text { Kjeldsen, } 2018\end{array}$ \\
\hline $\begin{array}{l}\text { Incidence and severity of } \\
\text { HT }\end{array}$ & $\uparrow$ & $\downarrow$ & Anand et al., 2008 \\
\hline Cardiac adaptation to HT & $\begin{array}{c}\text { Eccentric } \\
\text { hypertrophy }\end{array}$ & $\begin{array}{l}\text { Concentric } \\
\text { hypertrophy }\end{array}$ & $\begin{array}{l}\text { Krumholz et al., 1993; } \\
\text { Santos and Shah, 2014 }\end{array}$ \\
\hline HF failure risk & $\downarrow$ & $\uparrow$ & Beale et al., 2018 \\
\hline \multicolumn{4}{|l|}{ Glucose metabolism } \\
\hline Basal insulin level & $\downarrow$ & $\uparrow$ & $\begin{array}{l}\text { Flanagan et al., 2006; } \\
\text { Reichelt et al., } 2013\end{array}$ \\
\hline Risk of diabetes & $\uparrow$ & $\downarrow$ & $\begin{array}{l}\text { International Diabetes } \\
\text { Federation, } 2019\end{array}$ \\
\hline \multicolumn{4}{|l|}{ Presence of diabetes } \\
\hline \multicolumn{4}{|l|}{ Fat distribution } \\
\hline Preferential localization & Visceral & Visceral & $\begin{array}{l}\text { Power and Schulkin, } \\
2008\end{array}$ \\
\hline Risk of CADs with obesity & $\downarrow$ & $\uparrow$ & $\begin{array}{l}\text { Elffers et al., 2017; Lind } \\
\text { et al., } 2017\end{array}$ \\
\hline Cardiac lipid level & $\downarrow$ & $\uparrow$ & lozzo et al., 2009 \\
\hline \multicolumn{4}{|l|}{ Blood pressure } \\
\hline $\begin{array}{l}\text { Incidence and severity of } \\
\text { HT }\end{array}$ & $\downarrow$ & $\uparrow$ & Anand et al., 2008 \\
\hline \multicolumn{4}{|l|}{ Glucose metabolism } \\
\hline Manifestation & $\begin{array}{l}\text { Impaired } \\
\text { fasting } \\
\text { blood } \\
\text { glucose }\end{array}$ & $\begin{array}{l}\text { Impaired } \\
\text { glucose } \\
\text { tolerance }\end{array}$ & Rydén et al., 2007 \\
\hline Insulin resistance & $\downarrow$ & $\uparrow$ & $\begin{array}{l}\text { Flanagan et al., 2006; } \\
\text { Reichelt et al., } 2013\end{array}$ \\
\hline CV risk with prediabetes & - & $\uparrow$ & Levitzky et al., 2008 \\
\hline
\end{tabular}

Arrows in the "male" column indicate differences in comparison to female; and arrows in the "female" column indicate differences in comparison to male. CV, cardiovascular; CADs, Coronary artery diseases; HF, heart failure; HT, hypertension.

of type 2 diabetes and CV complications. Diabetic women present higher insulin resistance (Flanagan et al., 2006; Reichelt et al., 2013) and are more likely to be glucose intolerant, and diabetic men have elevated fasting blood glucose levels (Rydén et al., 2007). Estrogen supplementation in postmenopausal women decreases fasting blood glucose and, thus, improves glucose tolerance (Huang et al., 2017). Ovariectomized Sprague-Dawley 
females had poorer glucose tolerance than non-ovariectomized animals (Saengsirisuwan et al., 2009). Importantly, prediabetes (fasting blood glucose: $100-125 \mathrm{mg} / \mathrm{dL}$ ) is predictive of CVDs only in women (Levitzky et al., 2008). The greater insulin resistance found in women, coupled with endothelial dysfunction, may explain the high risk of $\mathrm{CV}$ complications in T2D (Rutter et al., 2003).

Importantly, obesity increases the relative risk of CADs by $64 \%$ in women as opposed to $46 \%$ in men (Elffers et al., 2017; Lind et al., 2017). Besides this, visceral adipose tissue is the source of ectopic deposition of fat in the heart (Tchernof and Despres, 2013), participating in the development of DCM through lipotoxicity (Listenberger et al., 2001; Bugger and Abel, 2014). T2D women have a more pronounced increase in intracardiac lipid content than T2D men (Iozzo et al., 2009). The ER $\beta$ receptor prevalence results in an adipogenic and diabetogenic profile (Blüher, 2013; Davis et al., 2013), probably explaining this difference.

Rutter et al. (2003) show that the increase in left ventricular mass and wall thickness correlating to glucose intolerance is more important in women than in men, largely accounted for by obesity and pressure overload. Hypertension is more pronounced in T2D women than in T2D men, and sex appears to influence morphological cardiac adaptation to hypertension (Santos and Shah, 2014). Women tend to develop concentric hypertrophy compared with men who tend to develop eccentric hypertrophy (Krumholz et al., 1993). This is confirmed in animal models (Olsson et al., 2001). A decrease in peroxisome proliferatoractivated receptor- $\alpha(\operatorname{PPAR} \alpha)$ signaling is found in hypertrophic males but not in females (Harrington et al., 2017), and acute inhibition of PPAR $\alpha$ blocks the sex difference in hypertrophy development. Accordingly, in humans suffering from aortic stenosis, Kararigas et al. (2014) reveal that cardiac hypertrophy is related to increased activation of profibrotic and inflammatory markers in men compared with women.

\section{SEXUAL DIMORPHISM IN ISCHEMIC HEART DISEASES ASSOCIATED WITH DIABETES}

In the general population, incidence of MI remains higher in men than in women. CVDs appear on average 10 years earlier in men than in women (Kannel and McGee, 1979; Thom et al., 2006; Anand et al., 2008; Dantas et al., 2012). Interestingly, women seem to lose this sex-related protection in the presence of T2D (Murphy, 2011). This could be primarily due to differences in diagnosis and treatment of MI itself. Symptoms experienced by women are, in $50 \%$ of cases, different from the classic symptoms recognized in men, such as feelings of exhaustion, digestive disorders, and shortness of breath (Mehta et al., 2016), resulting in delayed treatment (Bugiardini et al., 2017). When considering CADs, women have a $50 \%$ higher risk than men, presenting increased mortality when exposed to acute MI (Kannel, 1987; Toedebusch et al., 2018) with a strong impact of long-standing diabetes in women (Natarajan et al., 2005). Several studies show a higher risk of CADs at lower glucose levels in women
(Koro et al., 2008; Levitzky et al., 2008). The Framingham study also demonstrated that risk of $\mathrm{MI}$ is increased by five in T2D women compared with non-diabetic women, and this risk is only multiplied by two in T2D men (Kannel et al., 1974; Wannamethee et al., 2012). Moreover, 38\% of women die within 1 year of their first MI although only $25 \%$ of men do so (Thom et al., 2006).

Concomitant development of atherosclerosis, endothelial dysfunction, and impairment of the coagulation profile could explain, in part, why diabetic women present a higher risk of ischemic heart diseases (IHDs). Clinical studies reveal a more severe atherogenic dyslipidemia in diabetic women, particularly through an increase in triglycerides and lipoprotein cholesterol concentrations (Walden et al., 1984). Accumulation of oxidized low-density lipoprotein within arteries is a mechanism contributing to the development of atherosclerotic plaques. In particular, Chen et al. (2002) show that its receptor, the lectinlike oxidized low-density lipoprotein receptor-1 (LOX-1), has an important role in atherosclerosis development. Interestingly, sex differences in LOX-1 are reported with a particularly high expression in diabetic and obese women (Brinkley et al., 2008), making it an interesting pathway related to sex differences in diabetes and IHDs.

Atherosclerosis is an important factor contributing to the development of endothelial dysfunction. Diabetic women are also characterized by greater endothelium impairment in comparison to diabetic men. Clinical studies particularly show endotheliumdependent vasodilation alteration, which is confirmed in different animal models of T2D (Alameddine et al., 2015; Ranucci et al., 2019). A decrease in endothelium-dependent and -independent vascular response is observed in female Goto-Kakizaki rats with lower coronary flow and reduced upregulation of the NO pathway (Desrois et al., 2017; Palee et al., 2017). Zhang et al. reveal a predisposition of females to vascular lesions after induction of diabetes in both mesenteric arteries and the aorta (Zhang et al., 2012; Hunter et al., 2017). Regulation of the protein kinase B pathway may also contribute to vascular endothelial dysfunction and myocardial sensitivity to an ischemia-reperfusion episode (Desrois et al., 2004), especially in females (Reichelt et al., 2013). Goel et al. (2008) suggest that estrogen causes genderspecific endothelial dysfunction in hyperglycemic conditions by increasing the expression of PKC $\beta$ and increasing $\mathrm{O}_{2}{ }^{-}$ production in females. Hyperglycemia also alters the balance of estrogen receptors and increases both oxidative stress and the level of vasoconstrictors (Donahue et al., 2007; Wannamethee et al., 2012; Hunter et al., 2017).

Interaction between endothelial impairment and platelet aggregation is also implicated in atherosclerosis pathogenesis. Diabetic women present elevation of fibrinolytic/thrombotic factors during the transition from normoglycemia to diabetes (Steinberg et al., 2000; Donahue et al., 2007, 2011), leading to a prothrombotic coagulation profile (Steinberg et al., 2000; Donahue et al., 2007). Meigs et al. report an increase in circulating levels of thrombosis-promoting factors (Plasminogen activator inhibitor-1, von Willebrand factor) and adhesion molecules (vascular cell adhesion molecule 1, intercellular adhesion molecule 1) associated with atherosclerosis and microvascular diseases (Meigs et al., 2006; Madhu, 2010). In addition, women 
with T2D are more sensitive to changes in coagulation and inflammation than men, which could be explained by the fact that women have a larger platelet count as well as higher platelet reactivity than men (Ranucci et al., 2019). Together, concomitant development of atherosclerosis, endothelial dysfunction, and impairment of the coagulation profile lead to a favorable environment for IHD development in diabetic women (Figure 1).

Mechanisms involved in increased mortality following myocardial infarction in diabetic women are not fully understood. Nevertheless, energy metabolism has recently emerged to explain this sex difference (Figure 1). A strong decrease in ATP and phosphocreatine cardiac content has been observed following ischemia-reperfusion injury in prediabetic female rats fed with a high-fat, high-sucrose diet and in diabetic GK female rats (Fourny et al., 2019a,b). Importantly a previous study reports no difference in high-energy compounds following ischemia-reperfusion injury in male GK (Desrois et al., 2010), suggesting the important role of mitochondria and particularly the energy production pathway in female sensitivity to IHDs.

\section{SEXUAL DIMORPHISM IN HEART FAILURE ASSOCIATED WITH DIABETES}

Heart failure is driven by CADs but also by aging, hypertension, diabetes, and obesity (Ho et al., 2016; Beale et al., 2018; Seferović et al., 2018). The excess risk of HF associated with diabetes is significantly greater in women with diabetes than in diabetic men (Ohkuma et al., 2019), increasing HF risk fivefold in women compared to 2.4-fold in men (Beale et al., 2018). Kim et al. (2019) also show that the impact of diabetes on long-term mortality and HF readmission seems to be greater in females than in males. Women represent $\sim 60 \%$ of patients having HF with preserved ejection fraction (HFpEF) whether they present with diabetes or not, but T2D women are younger, more obese, have worse renal function, lower prevalence of atrial fibrillation, and decreased hemoglobin levels (Lejeune et al., 2021). Importantly, HFpEF is more prevalent in women than in men, who preferentially exert
HF with reduced ejection fraction (Beale et al., 2019; Dewan et al., 2019). In line, Weinberg et al. (1999) show sex-related differences in genes regulating calcium handling and contractile function. Males have higher beta-myosin heavy chain and atrial natriuretic factor, and lower SERCA-2 mRNAs in comparison with females despite a similar left ventricular hypertrophy and systolic overload (Weinberg et al., 1999).

Besides CADs and hypertension, the diabetic heart is characterized by alterations of its structure and mass as well as of its diastolic and systolic function, leading to the concept of DCM (Boudina and Abel, 2010). Interestingly, DCM prevalence is higher in women in comparison to men. In particular, Kiencke et al. (2010) show that female gender is an independent risk factor for DCM, characterized by greater structural and functional impairment (Kiencke et al., 2010; Toedebusch et al., 2018; Figure 1).

Myocardial remodeling occurs during DCM development with an increase in fibrosis and collagen I and III deposits, leading to myocardial rigidity (Murphy et al., 2017). Studies show greater myocardial remodeling and fibrosis in women with HF compared with men (Li et al., 2017). Women with T2D have greater cardiac hypertrophy, myocardial wall thickening, and an increase in left ventricular mass. Greater hypertrophy is also observed in female GK rats compared with males (Desrois et al., 2004). Estrogen receptor $E R \beta$ is shown to play an important role in the regulation of collagen levels (Schuster et al., 2016). Schuster et al. (2016) reveal that overexpression of $E R \beta$ in mice reduced myocardial fibrosis and collagen I/III deposits, improving cardiac function. Inversely, Skavdahl et al. (2005) detect basal cardiac hypertrophy in female mice deficient for $\mathrm{ER} \beta$, confirming the important role of this receptor for cardiac hypertrophy development in females. Moreover, imbalance between ER $\alpha$ and $\operatorname{ER} \beta$ is reported in diabetic women and may explain the loss of estrogen cardioprotection regarding myocardial hypertrophy and fibrosis in DCM (Wells et al., 2005).

A fined-tuned regulation of metabolism and energy production is essential for heart function (Horman et al., 2012; Bertrand et al., 2020). Female cardiomyocytes contain
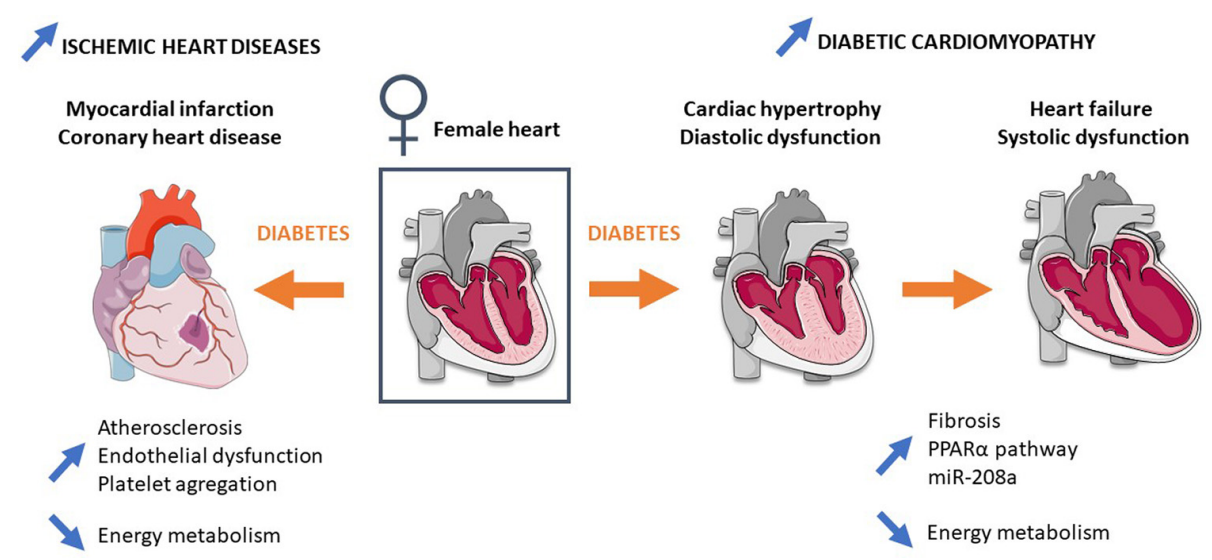

FIGURE 1 | Mechanisms involved in the higher risk and mortality of type 2 diabetic women in ischemic heart diseases and diabetic cardiomyopathy. Detailed information is provided in the main text. Blue arrows represent differences in comparison to diabetic men. 
less mitochondria, but they are more efficient than in male cardiomyocytes. Female hearts use fatty acids for energy production in greater proportion than males (Djouadi et al., 1998; Ventura-Clapier et al., 2017b). They also produce fewer ROS, have a lower calcium uptake rate, and a greater calcium retention capacity (Ventura-Clapier et al., 2017b). This sexual dimorphism does not lead to a difference in respiration and mitochondrial efficiency in the basal state but could play a role in pathological situations such as DCM. Of interest, a mitochondrial localization of estrogen receptors is reported, inducing direct effects of estrogen on mitochondrial respiration and antioxidant defenses (Gupte et al., 2015). Billimoria et al. (2006) show a greater mitochondrial respiration in female streptozotocintreated (STZ) rats in comparison with corresponding males. Lagranha et al. (2010) show that the phosphorylation level of mitochondrial proteins is more important in females compared with males. This is particularly the case for the aldehyde dehydrogenase 2, leading to a decrease in ROS production (Lagranha et al., 2010; Tchernof and Despres, 2013).

Metabolic inflexibility is commonly noticed in the diabetic heart, which mainly relies on fatty acid oxidation for energy production (Vallerie and Bornfeldt, 2015). The increase in fatty acid oxidation in the diabetic heart is associated with an increase in PPAR $\alpha$, which plays a key role in the development of cardiac hypertrophy and dysfunction in DCM (Madrazo and Kelly, 2008; Bayeva et al., 2013). Interestingly, estrogen is involved in the signaling pathway of lipid metabolism and may explain the differences in mitochondrial metabolism observed between diabetic males and females. Indeed, Djouadi et al. (1998) show, in PPAR $\alpha^{-/-}$mice, that the subsequent inhibition of cellular fatty acid metabolism caused massive accumulation of hepatic and cardiac lipids, hypoglycemia, and death in $100 \%$ of males but only $25 \%$ of females. The treatment with $\beta$-estradiol decreased the mortality in males, demonstrating the role of female sex hormones in lipid homeostasis mediated by PPAR $\alpha$ (Djouadi et al., 1998). In the last decade, micro-RNAs emerged as biomarkers of DCM and targets for new treatment. Yin et al. (2019) show that miR-30c protects cardiac metabolism and function in diabetes through $\operatorname{PPAR} \alpha$ modulation and its downstream effector, the co-activator Peroxisome proliferatoractivated receptor gamma coactivator 1-alpha (PGC1 $\alpha)$. The miR-208a, whose overexpression induced spontaneous cardiac hypertrophy (Callis et al., 2009), is another miR playing a role in DCM. Recently, Lum-Naihe et al. (2017) highlighted higher miR-208a expression in female diabetic hearts than in male counterparts.

\section{PERSONALIZED CARE OF DIABETIC PATIENTS}

Involvement of female hormones in various physiological and pathophysiological processes has led the scientific community to focus their research on the male sex. However, we currently know that women have a different clinical presentation and drug response in multiple pathologies, including CVDs and T2D (Mathieu et al., 2018; Fourny et al., 2019b). First, clinical trials demonstrated sex differences in lifestyle intervention in diabetic patients. Moderate-intensity resistance exercise training is a more favorable approach for hypertensive women because of greater decreases in diastolic blood pressure and significant increases in flow-mediated dilation compared with their male counterparts (Collier et al., 2011). Weight loss with intensive lifestyle modification led to greater decreases in glucose/insulin concentration, insulin resistance, triglyceride, and glycated hemoglobin HbAlc levels in men than in women, indicating that women should particularly pay attention to risk factors, such as obesity (Perreault et al., 2008). This was confirmed in animal models in which diet change is most effective to reduce inflammation in male mice (Griffin et al., 2019).

Sex differences are also reported in regard to the response to antidiabetic drugs. In young patients, metformin plus rosiglitazone was more effective in girls than in boys (Zeitler et al., 2012). In adults, women had a higher reduction of body weight after treatment with metformin or sulfonylurea, whereas men displayed higher $\mathrm{HbA} 1 \mathrm{c}$ reduction after treatment with metformin only (Schütt et al., 2015). Sex differences were also reported for incretins with a better glycemic control in men (Anichini et al., 2013) while others showed greater weight loss, reductions of fasting glucose, and blood pressure levels in women (Pencek et al., 2012). The LEADER study highlighted a greater $\mathrm{CV}$ benefit in men than in women with liraglutide treatment (Verma et al., 2018). Recently, Raparelli et al. (2020) demonstrated greater CV effectiveness of GLP-1 receptor agonist in women. However, "the real-world experience" study showed that men achieved target glycemic response in higher proportions than women after 1 year of exenatide (Anichini et al., 2013). A greater glycemic response and $\mathrm{HbAlc}$ reduction was found with sulfonylureas than with thiazolidinediones in men, whereas female sex was associated with greater $\mathrm{HbAlc}$ reduction but a weight gain and edema risk with thiazolidinediones (Dennis et al., 2018). Interestingly, Zinman et al. (2015) reported no sex difference in the EMPA-REG OUTCOME trial in effects of a sodium-glucose cotransporter 2 inhibitor. However, subgroup analysis showed a significant CV benefit in males only (KautzkyWiller and Harreiter, 2017). In 2020, an important study showed no differences for vascular efficacy outcomes or death with major protection against major adverse CV events, HF, vascular death, and total mortality in both men and women (Rådholm et al., 2020). Taken together, these studies clearly show that sex should be considered in the choice of antidiabetic treatment to move toward "precision medicine," which aims to treat patients with accurate care that is more personalized and including individual variability (Currie and Delles, 2018; Prasad and Groop, 2019). However, mechanisms involved in these differences are not yet understood, and disparity of antidiabetic treatments used, alone or in combination, makes comparison difficult.

The choice of the animal model to be employed is also delicate for the efficient transfer of results to humans, particularly when comparing males and females. Indeed, studying females is not always possible in animal T2D models. For example, the female TallyHo mouse does not show hyperglycemia unlike males (Kim et al., 2005) and the female Nagoya-Shibata-Yasuda mouse has a low incidence of type 2 diabetes compared with 
males (Ueda et al., 1995). Besides this, enriched diets are also commonly used in the literature, but their diversity and duration make comparison difficult. Thus, each diet-induced and energetic diabetic model should be well characterized to ensure good interpretation of the results obtained in both sexes.

\section{CONCLUSION}

In conclusion, clinical and animal studies clearly indicate that there are sex differences in T2D-associated CV complications. However, the precise molecular mechanisms responsible for these differences are still largely blurred. Recent studies have particularly emphasized the link between energy metabolism and miRs. Thus, future studies should particularly pay attention to the metabolic dysfunctions that are involved in both IHDs and DCM development. This could provide new targets for the treatment of the diabetic heart. In addition, the antidiabetic drug response also differs significantly according to sex. Therefore, the scientific community must include both sexes in future clinical trials and

\section{REFERENCES}

Alameddine, A., Fajloun, Z., Bourreau, J., Gauquelin-Koch, G., Yuan, M., Gauguier, D., et al. (2015). The cardiovascular effects of salidroside in the Goto-Kakizaki diabetic rat model. J. Physiol. Pharmacol. 66, 249-257.

American Diabetes Association (2015). (8) Cardiovascular disease and risk management. Diabetes Care 38 Suppl, S49-S57.

Anand, S. S., Islam, S., Rosengren, A., Franzosi, M. G., Steyn, K., Yusufali, A. H., et al. (2008). Risk factors for myocardial infarction in women and men: insights from the INTERHEART study. Eur. Heart J. 29, 932-940. doi: 10.1093/ eurheartj/ehn018

Anichini, R., Cosimi, S., Di Carlo, A., Orsini, P., De Bellis, A., Seghieri, G., et al. (2013). Gender difference in response predictors after 1-year exenatide therapy twice daily in type 2 diabetic patients: a real world experience. Diabetes Metab. Syndr. Obes. 6, 123-129. doi: 10.2147/dmso.s42729

Bayeva, M., Sawicki, K. T., and Ardehali, H. (2013). Taking diabetes to heartderegulation of myocardial lipid metabolism in diabetic cardiomyopathy. J. Am. Heart Assoc. 2:e000433.

Beale, A. L., Meyer, P., Marwick, T. H., Lam, C. S. P., and Kaye, D. M. (2018). Sex differences in cardiovascular pathophysiology: why women are overrepresented in heart failure with preserved ejection fraction. Circulation 138, 198-205. doi: 10.1161/circulationaha.118.034271

Beale, A. L., Nanayakkara, S., Segan, L., Mariani, J. A., Maeder, M. T., van Empel, V., et al. (2019). Sex differences in heart failure with preserved ejection fraction pathophysiology: a detailed invasive hemodynamic and echocardiographic analysis. JACC Heart Fail. 7, 239-249.

Bertrand, L., Auquier, J., Renguet, E., Angé, M., Cumps, J., Horman, S., et al. (2020). Glucose transporters in cardiovascular system in health and disease. Pflugers. Arch. 472, 1385-1399.

Billimoria, F. R., Katyare, S. S., and Patel, S. P. (2006). Insulin status differentially affects energy transduction in cardiac mitochondria from male and female rats. Diabetes Obes Metab. 8, 67-74. doi: 10.1111/j.1463-1326.2005.00470.x

Blenck, C. L., Harvey, P. A., Reckelhoff, J. F., and Leinwand, L. A. (2016). The importance of biological sex and estrogen in rodent models of cardiovascular health and disease. Circ. Res. 118, 1294-1312. doi: 10.1161/circresaha.116. 307509

Blüher, M. (2013). Importance of estrogen receptors in adipose tissue function. Mol. Metab. 2, 130-132. doi: 10.1016/j.molmet.2013.07.001

Boudina, S., and Abel, E. D. (2010). Diabetic cardiomyopathy, causes and effects. Rev. Endocr. Metab. Disord. 11, 31-39. doi: 10.1007/s11154-010-9131-7

Brinkley, T. E., Kume, N., Mitsuoka, H., Phares, D. A., and Hagberg, J. M. (2008). Elevated soluble lectin-like oxidized LDL receptor-1 (sLOX-1) levels in obese animal studies to improve quality of care and bring a more personalized treatment to each patient.

\section{AUTHOR CONTRIBUTIONS}

All authors listed have made a substantial, direct and intellectual contribution to the work, and approved it for publication.

\section{FUNDING}

This work was funded by grants from the Fonds National de la Recherche Scientifique (FNRS) et Médicale and Belgium and Action de Recherche Concertée de la Communauté WallonieBruxelles, Belgium. The authors declare that this study received funding from AstraZeneca. The funder was not involved in the study design, collection, analysis, interpretation of data, and the writing of this article or the decision to submit it for publication. $\mathrm{SH}$ is senior research associate of the FNRS.

postmenopausal women. Obesity (Silver Spring) 16, 1454-1456. doi: 10.1038/ oby. 2008.213

Bugger, H., and Abel, E. D. (2014). Molecular mechanisms of diabetic cardiomyopathy. Diabetologia 57, 660-671. doi: 10.1007/s00125-014-3171-6

Bugiardini, R., Ricci, B., Cenko, E., Vasiljevic, Z., Kedev, S., Davidovic, G., et al. (2017). Delayed care and mortality among women and men with myocardial infarction. J. Am. Heart Assoc. 6:e005968.

Callis, T. E., Pandya, K., Seok, H. Y., Tang, R. H., Tatsuguchi, M., Huang, Z. P., et al. (2009). MicroRNA-208a is a regulator of cardiac hypertrophy and conduction in mice. J. Clin. Invest. 119, 2772-2786.

Chen, M., Masaki, T., and Sawamura, T. (2002). LOX-1, the receptor for oxidized low-density lipoprotein identified from endothelial cells: implications in endothelial dysfunction and atherosclerosis. Pharmacol. Ther. 95, 89-100. doi: 10.1016/s0163-7258(02)00236-x

Cid, M. C., Schnaper, H. W., and Kleinman, H. K. (2002). Estrogens and the vascular endothelium. Ann. N. Y. Acad. Sci. 966, 143-157. doi: 10.1111/j.17496632.2002.tb04211.x

Collier, S. R., Frechette, V., Sandberg, K., Schafer, P., Ji, H., Smulyan, H., et al. (2011). Sex differences in resting hemodynamics and arterial stiffness following 4 weeks of resistance versus aerobic exercise training in individuals with prehypertension to stage 1 hypertension. Biol. Sex Differ. 2:9. doi: 10.1186/20426410-2-9

Currie, G., and Delles, C. (2018). Precision medicine and personalized medicine in cardiovascular disease. Adv. Exp. Med. Biol. 1065, 589-605. doi: 10.1007/9783-319-77932-4_36

Dantas, A. P., Fortes, Z. B., and de Carvalho, M. H. (2012). Vascular disease in diabetic women: why do they miss the female protection? Exp. Diabetes Res. 2012:570598.

Davis, K. E., Neinast, M. D., Sun, K., Skiles, W. M., Bills, J. D., Zehr, J. A., et al. (2013). The sexually dimorphic role of adipose and adipocyte estrogen receptors in modulating adipose tissue expansion, inflammation, and fibrosis. Mol. Metab. 2, 227-242. doi: 10.1016/j.molmet.2013.05.006

Dennis, J. M., Henley, W. E., Weedon, M. N., Lonergan, M., Rodgers, L. R., Jones, A. G., et al. (2018). Sex and BMI alter the benefits and risks of sulfonylureas and thiazolidinediones in type 2 diabetes: a framework for evaluating stratification using routine clinical and individual trial data. Diabetes Care 41, 1844-1853. doi: $10.2337 / \mathrm{dc} 18-0344$

Desrois, M., Clarke, K., Lan, C., Dalmasso, C., Cole, M., Portha, B., et al. (2010). Upregulation of eNOS and unchanged energy metabolism in increased susceptibility of the aging type 2 diabetic GK rat heart to ischemic injury. Am. J. Physiol. Heart Circ. Physiol. 299, H1679-H1686. 
Desrois, M., Lan, C., Movassat, J., and Bernard, M. (2017). Reduced up-regulation of the nitric oxide pathway and impaired endothelial and smooth muscle functions in the female type 2 diabetic goto-kakizaki rat heart. Nutr. Metab. (Lond.) 14:6

Desrois, M., Sidell, R. J., Gauguier, D., Davey, C. L., Radda, G. K., and Clarke, K. (2004). Gender differences in hypertrophy, insulin resistance and ischemic injury in the aging type 2 diabetic rat heart. J. Mol. Cell Cardiol. 37, 547-555. doi: 10.1016/j.yjmcc.2004.05.014

Dewan, P., Rørth, R., Raparelli, V., Campbell, R. T., Shen, L., Jhund, P. S., et al. (2019). Sex-related differences in heart failure with preserved ejection fraction. Circ. Heart Fail. 12:e006539.

Djouadi, F., Weinheimer, C. J., Saffitz, J. E., Pitchford, C., Bastin, J., Gonzalez, F. J., et al. (1998). A gender-related defect in lipid metabolism and glucose homeostasis in peroxisome proliferator- activated receptor alpha- deficient mice. J. Clin. Invest. 102, 1083-1091. doi: 10.1172/jci3949

Donahue, R. P., Dorn, J. M., Stranges, S., Swanson, M., Hovey, K., and Trevisan, M. (2011). Impaired fasting glucose and recurrent cardiovascular disease among survivors of a first acute myocardial infarction: evidence of a sex difference? The Western New York experience. Nutr. Metab. Cardiovasc. Dis. 21, 504-511. doi: 10.1016/j.numecd.2009.11.012

Donahue, R. P., Rejman, K., Rafalson, L. B., Dmochowski, J., Stranges, S., and Trevisan, M. (2007). Sex differences in endothelial function markers before conversion to pre-diabetes: does the clock start ticking earlier among women? The Western New York Study. Diabetes Care 30, 354-359. doi: 10.2337/dc061772

Elffers, T. W., de Mutsert, R., Lamb, H. J., de Roos, A., Willems van Dijk, K., Rosendaal, F. R., et al. (2017). Body fat distribution, in particular visceral fat, is associated with cardiometabolic risk factors in obese women. PLoS One 12:e0185403. doi: 10.1371/journal.pone.0185403

Eshak, E. S., Iso, H., Mizoue, T., Inoue, M., Noda, M., and Tsugane, S. (2013). Soft drink, $100 \%$ fruit juice, and vegetable juice intakes and risk of diabetes mellitus. Clin. Nutr. 32, 300-308. doi: 10.1016/j.clnu.2012.08.003

Flanagan, D. E., Holt, R. I., Owens, P. C., Cockington, R. J., Moore, V. M., Robinson, J. S., et al. (2006). Gender differences in the insulin-like growth factor axis response to a glucose load. Acta Physiol. (Oxf.) 187, 371-378. doi: 10.1111/j.1748-1716.2006.01581.x

Fourny, N., Lan, C., Kober, F., Boulghobra, D., Bresciani, J., Reboul, C., et al. (2019a). Cardiac remodeling and higher sensitivity to ischemia-reperfusion injury in female rats submitted to high-fat high-sucrose diet: an in vivo/ex vivo longitudinal follow-up. J. Nutr. Biochem. 69, 139-150. doi: 10.1016/j.jnutbio. 2019.03.022

Fourny, N., Lan, C., Sérée, E., Bernard, M., and Desrois, M. (2019b). Protective effect of resveratrol against ischemia-reperfusion injury via enhanced high energy compounds and eNOS-SIRT1 expression in type 2 diabetic female rat heart. Nutrients 11:105. doi: 10.3390/nu11010105

Garcia, M., Mulvagh, S. L., Merz, C. N., Buring, J. E., and Manson, J. E. (2016). Cardiovascular disease in women: clinical perspectives. Circ. Res. 118, 12731293. doi: 10.1161/circresaha.116.307547

Goel, A., Thor, D., Anderson, L., and Rahimian, R. (2008). Sexual dimorphism in rabbit aortic endothelial function under acute hyperglycemic conditions and gender-specific responses to acute 17beta-estradiol. Am. J. Physiol. Heart Circ. Physiol. 294, H2411-H2420.

Griffin, C., Hutch, C. R., Abrishami, S., Stelmak, D., Eter, L., Li, Z., et al. (2019). Inflammatory responses to dietary and surgical weight loss in male and female mice. Biol. Sex Differ. 10:16.

Gupte, A. A., Pownall, H. J., and Hamilton, D. J. (2015). Estrogen: an emerging regulator of insulin action and mitochondrial function. J. Diabetes Res. 2015:916585.

Harrington, J., Fillmore, N., Gao, S., Yang, Y., Zhang, X., Liu, P., et al. (2017). A systems biology approach to investigating sex differences in cardiac hypertrophy. J. Am. Heart Assoc. 6:e005838.

Ho, J. E., Enserro, D., Brouwers, F. P., Kizer, J. R., Shah, S. J., Psaty, B. M., et al. (2016). Predicting heart failure with preserved and reduced ejection fraction: the international collaboration on heart failure subtypes. Circ. Heart Fail. 9:e003116.

Horman, S., Beauloye, C., Vanoverschelde, J. L., and Bertrand, L. (2012). AMPactivated protein kinase in the control of cardiac metabolism and remodeling. Curr. Heart Fail. Rep. 9, 164-173. doi: 10.1007/s11897-012-0102-z
Huang, D., Refaat, M., Mohammedi, K., Jayyousi, A., Al Suwaidi, J., and Abi Khalil, C. (2017). Macrovascular complications in patients with diabetes and prediabetes. Biomed. Res. Int. 2017:7839101.

Hunter, I., Soler, A., Joseph, G., Hutcheson, B., Bradford, C., Zhang, F. F., et al. (2017). Cardiovascular function in male and female JCR:LA-cp rats: effect of high-fat/high-sucrose diet. Am. J. Physiol. Heart Circ. Physiol. 312, H742-H751.

International Diabetes Federation (2019). IDF Diabetes Atlas, t.e.B. Brussels: International Diabetes Federation.

Iorga, A., Cunningham, C. M., Moazeni, S., Ruffenach, G., Umar, S., and Eghbali, M. (2017). The protective role of estrogen and estrogen receptors in cardiovascular disease and the controversial use of estrogen therapy. Biol. Sex Differ. 8:33.

Iozzo, P., Lautamaki, R., Borra, R., Lehto, H. R., Bucci, M., Viljanen, A., et al. (2009). Contribution of glucose tolerance and gender to cardiac adiposity. J. Clin. Endocrinol. Metab. 94, 4472-4482. doi: 10.1210/jc.2009-0436

Kander, M. C., Cui, Y., and Liu, Z. (2017). Gender difference in oxidative stress: a new look at the mechanisms for cardiovascular diseases. J. Cell Mol. Med. 21, 1024-1032. doi: $10.1111 /$ jcmm. 13038

Kannel, W. B. (1987). Metabolic risk factors for coronary heart disease in women: perspective from the Framingham study. Am. Heart J. 114, 413-419. doi: 10.1016/0002-8703(87)90511-4

Kannel, W. B., Hjortland, M., and Castelli, W. P. (1974). Role of diabetes in congestive heart failure: the Framingham study. Am. J. Cardiol. 34, 29-34. doi: 10.1016/0002-9149(74)90089-7

Kannel, W. B., and McGee, D. L. (1979). Diabetes and cardiovascular disease. The Framingham study. JAMA 241, 2035-2038. doi: 10.1001/jama.1979. 03290450033020

Kararigas, G., Dworatzek, E., Petrov, G., Summer, H., Schulze, T. M., Baczko, I., et al. (2014). Sex-dependent regulation of fibrosis and inflammation in human left ventricular remodelling under pressure overload. Eur. J. Heart Fail. 16, 1160-1167. doi: 10.1002/ejhf.171

Kautzky-Willer, A., and Harreiter, J. (2017). Sex and gender differences in therapy of type 2 diabetes. Diabetes Res. Clin. Pract. 131, 230-241. doi: 10.1016/j.diabres. 2017.07.012

Kautzky-Willer, A., Harreiter, J., and Pacini, G. (2016). Sex and gender differences in risk, pathophysiology and complications of type 2 diabetes mellitus. Endocr. Rev. 37, 278-316. doi: 10.1210/er.2015-1137

Kiencke, S., Handschin, R., von Dahlen, R., Muser, J., Brunner-Larocca, H. P., Schumann, J., et al. (2010). Pre-clinical diabetic cardiomyopathy: prevalence, screening, and outcome. Eur. J. Heart Fail. 12, 951-957. doi: 10.1093/eurjhf/ hfq110

Kim, H. L., Kim, M. A., Park, K. T., Choi, D. J., Han, S., Jeon, E. S., et al. (2019). Gender difference in the impact of coexisting diabetes mellitus on long-term clinical outcome in people with heart failure: a report from the Korean Heart Failure Registry. Diabet. Med. 36, 1312-1318. doi: 10.1111/dme.1 4059

Kim, J. H., Stewart, T. P., Zhang, W., Kim, H. Y., Nishina, P. M., and Naggert, J. K. (2005). Type 2 diabetes mouse model TallyHo carries an obesity gene on chromosome 6 that exaggerates dietary obesity. Physiol. Genomics 22, 171-181. doi: 10.1152/physiolgenomics.00197.2004

Kjeldsen, S. E. (2018). Hypertension and cardiovascular risk: general aspects. Pharmacol Res. 129, 95-99. doi: 10.1016/j.phrs.2017.11.003

Koro, C. E., Bowlin, S. J., Rabatin, V., and Fedder, D. O. (2008). Cardiovascular disease risk among subjects with impaired fasting glucose in the United States: results from NHANES 1999-2004. Diabetes Metab. Syndr. 2, 239-244. doi: 10.1016/j.dsx.2008.07.003

Kriska, A. M., Edelstein, S. L., Hamman, R. F., Otto, A., Bray, G. A., Mayer-Davis, E. J., et al. (2006). Physical activity in individuals at risk for diabetes: diabetes prevention program. Med. Sci. Sports Exerc. 38, 826-832. doi: 10.1249/01.mss. 0000218138.91812.f9

Krumholz, H. M., Larson, M., and Levy, D. (1993). Sex differences in cardiac adaptation to isolated systolic hypertension. Am. J. Cardiol. 72, 310-313. doi: 10.1016/0002-9149(93)90678-6

Lagranha, C. J., Deschamps, A., Aponte, A., Steenbergen, C., and Murphy, E. (2010). Sex differences in the phosphorylation of mitochondrial proteins result in reduced production of reactive oxygen species and cardioprotection in females. Circ. Res. 106, 1681-1691. doi: 10.1161/circresaha.109.21 3645 
Lejeune, S., Roy, C., Slimani, A., Pasquet, A., Vancraeynest, D., Vanoverschelde, J. L., et al. (2021). Diabetic phenotype and prognosis of patients with heart failure and preserved ejection fraction in a real life cohort. Cardiovasc. Diabetol. 20:48.

Levitzky, Y. S., Pencina, M. J., D’Agostino, R. B., Meigs, J. B., Murabito, J. M., Vasan, R. S., et al. (2008). Impact of impaired fasting glucose on cardiovascular disease: the Framingham heart study. J. Am. Coll. Cardiol. 51, 264-270.

Li, Z., Wang, Z., Yin, Z., Zhang, Y., Xue, X., Han, J., et al. (2017). Gender differences in fibrosis remodeling in patients with long-standing persistent atrial fibrillation. Oncotarget 8, 53714-53729. doi: 10.18632/oncotarget.16342

Lind, L., Ärnlöv, J., and Lampa, E. (2017). The interplay between fat mass and fat distribution as determinants of the metabolic syndrome is sex-dependent. Metab. Syndr. Relat. Disord. 15, 337-343. doi: 10.1089/met.2017.0006

Listenberger, L. L., Ory, D. S., and Schaffer, J. E. (2001). Palmitate-induced apoptosis can occur through a ceramide-independent pathway. J. Biol. Chem. 276, 14890-14895. doi: 10.1074/jbc.m010286200

Lum-Naihe, K., Toedebusch, R., Mahmood, A., Bajwa, J., Carmack, T., Kumar, S. A., et al. (2017). Cardiovascular disease progression in female Zucker Diabetic Fatty rats occurs via unique mechanisms compared to males. Sci. Rep. 7:17823.

Madhu, S. V. (2010). Endothelial dysfunction and diabetes. J. Assoc. Physicians India 58, 475-476.

Madrazo, J. A., and Kelly, D. P. (2008). The PPAR trio: regulators of myocardial energy metabolism in health and disease. J. Mol. Cell Cardiol. 44, 968-975. doi: 10.1016/j.yjmcc.2008.03.021

Mathieu, C., Desrois, M., Kober, F., Lalevée, N., Lan, C., Fourny, N., et al. (2018). Sex-mediated response to the beta-blocker landiolol in sepsis: an experimental, randomized study. Crit. Care Med. 46, e684-e691.

Mehta, L. S., Beckie, T. M., DeVon, H. A., Grines, C. L., Krumholz, H. M., Johnson, M. N., et al. (2016). Acute myocardial infarction in women: a scientific statement from the american heart association. Circulation 133, 916-947. doi: 10.1161/cir.0000000000000351

Meigs, J. B., O’Donnell, C. J., Tofler, G. H., Benjamin, E. J., Fox, C. S., Lipinska, I., et al. (2006). Hemostatic markers of endothelial dysfunction and risk of incident type 2 diabetes: the Framingham offspring study. Diabetes 55, 530-537. doi: 10.2337/diabetes.55.02.06.db05-1041

Murphy, E. (2011). Estrogen signaling and cardiovascular disease. Circ. Res. 109, 687-696. doi: 10.1161/circresaha.110.236687

Murphy, E., Amanakis, G., Fillmore, N., Parks, R. J., and Sun, J. (2017). Sex differences in metabolic cardiomyopathy. Cardiovasc. Res. 113, 370-377. doi: $10.1093 / \mathrm{cvr} / \mathrm{cvx} 008$

Natarajan, S., Liao, Y., Sinha, D., Cao, G., McGee, D. L., and Lipsitz, S. R. (2005). Sex differences in the effect of diabetes duration on coronary heart disease mortality. Arch. Intern. Med. 165, 430-435. doi: 10.1001/archinte.165.4.430

Ohkuma, T., Komorita, Y., Peters, S. A. E., and Woodward, M. (2019). Diabetes as a risk factor for heart failure in women and men: a systematic review and meta-analysis of 47 cohorts including 12 million individuals. Diabetologia 62, 1550-1560. doi: 10.1007/s00125-019-4926-x

Olsson, M. C., Palmer, B. M., Leinwand, L. A., and Moore, R. L. (2001). Gender and aging in a transgenic mouse model of hypertrophic cardiomyopathy. Am. J. Physiol. Heart Circ. Physiol. 280, H1136-H1144.

Palee, S., Minta, W., Mantor, D., Sutham, W., Pratchayasakul, W., Chattipakorn, S., et al. (2017). Estrogen deprivation aggravates cardiometabolic dysfunction and intracellular calcium dyshomeostasis in obese-insulin resistance rats. J. Am. Coll. Cardiol. 69:681. doi: 10.1016/s0735-1097(17)34070-6

Pencek, R., Blickensderfer, A., Li, Y., Brunell, S. C., and Chen, S. (2012). Exenatide once weekly for the treatment of type 2 diabetes: effectiveness and tolerability in patient subpopulations. Int. J. Clin. Pract. 66, 1021-1032. doi: 10.1111/j.17421241.2012.03006.X

Perreault, L., Ma, Y., Dagogo-Jack, S., Horton, E., Marrero, D., Crandall, J., et al. (2008). Sex differences in diabetes risk and the effect of intensive lifestyle modification in the diabetes prevention program. Diabetes Care 31, 1416-1421. doi: $10.2337 / \mathrm{dc} 07-2390$

Power, M. L., and Schulkin, J. (2008). Sex differences in fat storage, fat metabolism, and the health risks from obesity: possible evolutionary origins. Br. J. Nutr. 99, 931-940. doi: 10.1017/s0007114507853347

Prasad, R. B., and Groop, L. (2019). Precision medicine in type 2 diabetes. J. Intern. Med. 285, 40-48. doi: 10.1111/joim.12859
Rådholm, K., Zhou, Z., Clemens, K., Neal, B., and Woodward, M. (2020). Effects of sodium-glucose co-transporter- 2 inhibitors in type 2 diabetes in women versus men. Diabetes Obes. Metab. 22, 263-266. doi: 10.1111/dom.13876

Ranucci, M., Aloisio, T., Di Dedda, U., Menicanti, L., de Vincentiis, C., and Baryshnikova, E. (2019). Gender-based differences in platelet function and platelet reactivity to P2Y12 inhibitors. PLoS One 14:e0225771. doi: 10.1371/ journal.pone.0225771

Raparelli, V., Elharram, M., Moura, C. S., Abrahamowicz, M., Bernatsky, S., Behlouli, H., et al. (2020). Sex differences in cardiovascular effectiveness of newer glucose-lowering drugs added to metformin in type 2 diabetes mellitus. J. Am. Heart Assoc. 9:e012940.

Reichelt, M. E., Mellor, K. M., Bell, J. R., Chandramouli, C., Headrick, J. P., and Delbridge, L. M. (2013). Sex, sex steroids, and diabetic cardiomyopathy: making the case for experimental focus. Am. J. Physiol. Heart Circ. Physiol. 305, H779-H792.

Rutter, M. K., Parise, H., Benjamin, E. J., Levy, D., Larson, M. G., Meigs, J. B., et al. (2003). Impact of glucose intolerance and insulin resistance on cardiac structure and function: sex-related differences in the Framingham heart study. Circulation 107, 448-454. doi: 10.1161/01.cir.0000045671.62860.98

Rydén, L., Standl, E., Bartnik, M., Van den Berghe, G., Betteridge, J., de Boer, M. J., et al. (2007). Guidelines on diabetes, pre-diabetes, and cardiovascular diseases: executive summary. The Task Force on Diabetes and Cardiovascular Diseases of the European Society of Cardiology (ESC) and of the European Association for the Study of Diabetes (EASD). Eur. Heart J. 28, 88-136.

Saengsirisuwan, V., Pongseeda, S., Prasannarong, M., Vichaiwong, K., and Toskulkao, C. (2009). Modulation of insulin resistance in ovariectomized rats by endurance exercise training and estrogen replacement. Metabolism 58, 38-47. doi: 10.1016/j.metabol.2008.08.004

Santos, M., and Shah, A. M. (2014). Alterations in cardiac structure and function in hypertension. Curr. Hypertens Rep. 16:428.

Schuster, I., Mahmoodzadeh, S., Dworatzek, E., Jaisser, F., Messaoudi, S., Morano, I., et al. (2016). Cardiomyocyte-specific overexpression of oestrogen receptor $\beta$ improves survival and cardiac function after myocardial infarction in female and male mice. Clin. Sci. (Lond.) 130, 365-376. doi: 10.1042/cs20150609

Schütt, M., Zimmermann, A., Hood, R., Hummel, M., Seufert, J., Siegel, E., et al. (2015). Gender-specific effects of treatment with lifestyle, metformin or sulfonylurea on glycemic control and body weight: a german multicenter analysis on 9108 patients. Exp. Clin. Endocrinol. Diabetes 123, 622-626. doi: 10.1055/s-0035-1559608

Seferović, P. M., Petrie, M. C., Filippatos, G. S., Anker, S. D., Rosano, G., Bauersachs, J., et al. (2018). Type 2 diabetes mellitus and heart failure: a position statement from the Heart Failure Association of the European Society of Cardiology. Eur. J. Heart Fail. 20, 853-872.

Skavdahl, M., Steenbergen, C., Clark, J., Myers, P., Demianenko, T., Mao, L., et al. (2005). Estrogen receptor-beta mediates male-female differences in the development of pressure overload hypertrophy. Am. J. Physiol. Heart Circ. Physiol. 288, H469-H476.

Steinberg, H. O., Paradisi, G., Cronin, J., Crowde, K., Hempfling, A., Hook, G., et al. (2000). Type II diabetes abrogates sex differences in endothelial function in premenopausal women. Circulation 101, 2040-2046. doi: 10.1161/01.cir.101. 17.2040

Tchernof, A., and Despres, J. P. (2013). Pathophysiology of human visceral obesity: an update. Physiol. Rev. 93, 359-404. doi: 10.1152/physrev.00033.2011

Thom, T., Haase, N., Rosamond, W., Howard, V. J., Rumsfeld, J., Manolio, T., et al. (2006). Heart disease and stroke statistics-2006 update: a report from the American Heart Association Statistics Committee and Stroke Statistics Subcommittee. Circulation 113, e85-e151.

Thomas, D. (2017). [Cardiovascular risk of smoking by gender]. Presse. Med. 46, 681-687.

Toedebusch, R., Belenchia, A., and Pulakat, L. (2018). Diabetic cardiomyopathy: impact of biological sex on disease development and molecular signatures. Front. Physiol. 9:453. doi: 10.3389/fphys.2018.00453

Ueda, H., Ikegami, H., Yamato, E., Fu, J., Fukuda, M., Shen, G., et al. (1995). The NSY mouse: a new animal model of spontaneous NIDDM with moderate obesity. Diabetologia 38, 503-508. doi: 10.1007/s001250050312

Vallerie, S. N., and Bornfeldt, K. E. (2015). Metabolic flexibility and dysfunction in cardiovascular cells. Arterioscler. Thromb. Vasc. Biol. 35, e37-e42. 
Ventura-Clapier, R., Dworatzek, E., Seeland, U., Kararigas, G., Arnal, J. F., Brunelleschi, S., et al. (2017a). Sex in basic research: concepts in the cardiovascular field. Cardiovasc. Res. 113, 711-724. doi: 10.1093/cvr/cvx066

Ventura-Clapier, R., Moulin, M., Piquereau, J., Lemaire, C., Mericskay, M., Veksler, V., et al. (2017b). Mitochondria: a central target for sex differences in pathologies. Clin. Sci. (Lond.) 131, 803-822. doi: 10.1042/cs20160485

Verma, S., Poulter, N. R., Bhatt, D. L., Bain, S. C., Buse, J. B., Leiter, L. A., et al. (2018). Effects of liraglutide on cardiovascular outcomes in patients with type 2 diabetes mellitus with or without history of myocardial infarction or stroke. Circulation 138, 2884-2894.

Walden, C. E., Knopp, R. H., Wahl, P. W., Beach, K. W., and Strandness, E. Jr. (1984). Sex differences in the effect of diabetes mellitus on lipoprotein triglyceride and cholesterol concentrations. N. Engl. J. Med. 311, 953-959. doi: 10.1056/nejm198410113111505

Wannamethee, S. G., Papacosta, O., Lawlor, D. A., Whincup, P. H., Lowe, G. D., Ebrahim, S., et al. (2012). Do women exhibit greater differences in established and novel risk factors between diabetes and non-diabetes than men? The British Regional Heart Study and British Women's Heart Health Study. Diabetologia 55, 80-87. doi: 10.1007/s00125-011-2 284-4

Weinberg, E. O., Thienelt, C. D., Katz, S. E., Bartunek, J., Tajima, M., Rohrbach, S., et al. (1999). Gender differences in molecular remodeling in pressure overload hypertrophy. J. Am. Coll. Cardiol. 34, 264-273. doi: 10.1016/s0735-1097(99) 00165-5

Wells, C. C., Riazi, S., Mankhey, R. W., Bhatti, F., Ecelbarger, C., and Maric, C. (2005). Diabetic nephropathy is associated with decreased circulating estradiol levels and imbalance in the expression of renal estrogen receptors. Gend. Med. 2, 227-237. doi: 10.1016/s1550-8579(05)80052-x

Willi, C., Bodenmann, P., Ghali, W. A., Faris, P. D., and Cornuz, J. (2007). Active smoking and the risk of type 2 diabetes: a systematic review and meta-analysis. JAMA 298, 2654-2664. doi: 10.1001/jama.298.22.2654
Xing, D., Nozell, S., Chen, Y. F., Hage, F., and Oparil, S. (2009). Estrogen and mechanisms of vascular protection. Arterioscler. Thromb. Vasc. Biol. 29, 289295. doi: 10.1161/atvbaha.108.182279

Yang, Y., Wang, I. W., Turrentine, M., and Wang, M. (2018). Postischemic application of estrogen ameliorates myocardial damage in an in vivo mouse model. J. Surg. Res. 231, 366-372. doi: 10.1016/j.jss.2018.05.076

Yin, Z., Zhao, Y., He, M., Li, H., Fan, J., Nie, X., et al. (2019). MiR-30c/PGC$1 \beta$ protects against diabetic cardiomyopathy via PPAR $\alpha$. Cardiovasc. Diabetol. 18:7.

Zeitler, P., Hirst, K., Pyle, L., Linder, B., Copeland, K., Arslanian, S., et al. (2012). A clinical trial to maintain glycemic control in youth with type 2 diabetes. N. Engl. J. Med. 366, 2247-2256. doi: 10.1056/nejmoa1109333

Zhang, R., Thor, D., Han, X., Anderson, L., and Rahimian, R. (2012). Sex differences in mesenteric endothelial function of streptozotocin-induced diabetic rats: a shift in the relative importance of EDRFs. Am. J. Physiol. Heart Circ. Physiol. 303, H1183-H1198.

Zinman, B., Wanner, C., Lachin, J. M., Fitchett, D., Bluhmki, E., Hantel, S., et al. (2015). Empagliflozin, cardiovascular outcomes, and mortality in type 2 diabetes. N. Engl. J. Med. 373, 2117-2128.

Conflict of Interest: The authors declare that the research was conducted in the absence of any commercial or financial relationships that could be construed as a potential conflict of interest.

Copyright (c) 2021 Fourny, Beauloye, Bernard, Horman, Desrois and Bertrand. This is an open-access article distributed under the terms of the Creative Commons Attribution License (CC BY). The use, distribution or reproduction in other forums is permitted, provided the original author(s) and the copyright owner(s) are credited and that the original publication in this journal is cited, in accordance with accepted academic practice. No use, distribution or reproduction is permitted which does not comply with these terms. 